\title{
On the Effectiveness of Drug Prevention in School: Effects of Peerbased and Adult-Led Drug Prevention on Self Efficacy and Substance Use Among Secondary-School Students
}

\author{
Dorothea Stella-Kaiser $^{*}, 1$, Schörner Barbara ${ }^{2}$ and Giacomuzzi Salvatore ${ }^{3}$ \\ ${ }^{1} 1080$ Wien, Lerchenfelderstraße 144-146/3, Vienna, Austria \\ ${ }^{2}$ University of Applied Sciences Vienna, Austria \\ ${ }^{3}$ University of Innsbruck, Free University of Bozen, Bolzano, Italy
}

\begin{abstract}
The present study aims at comparing the influence of two different models of substance abuse prevention - a peer-based and an adult-based drug prevention program - on the self efficacy and substance abuse behaviour of secondary school students. The results of previous research suggest that the the peer-based drug prevention method might be more effective than the adult-led program in maximizing students' self-efficacy and reducing their substance consumption. A sample comprising 376 secondary school students of two different Viennese secondary schools was selected for implementing one of these two drug prevention models for a period of three years. The project was based on a longitudinal study that extended over four years and in which the subjects were made to answer a questionnaire containing 101 questions at five points in time. While the findings as a whole did not unambiguously confirm the greater efficacy of the peer-led programme, the main results indicate that the peer based programme had a positive impact on regular alcohol consumption, as at assessment timepoint 4 (end of intervention) $48 \%$ of the students in the adult-led programme, but only $33 \%$ of those in the peer-led programme were reported to drink alcohol regularly, a finding that is statistically significant. On the other hand, no influence on tobacco smoking was noted. While, in purely descriptive terms, the peer-led prevention model might have exhibited a positive influence on drug consumption over time, the difference from the adultled prevention model was not statistically significant. Concerning the second subject under investigation, the connection between self-efficacy and substance use, our findings suggest that - irrespective of the method of instruction - students with a high level of perceived self-efficacy were likely to show a lower level of substance use than their low-self-efficacy counterparts. This finding, however, applies only to individual assessment timepoints, not to the whole duration of the intervention. In any case, our results suggest that more studies are required to examine if there exists any evidence that students with a high level of self efficacy are more likely to show a lower level of substance abuse than those with a lower degree of self efficacy regarding substances other than alcohol.
\end{abstract}

Keywords: Adult-led drug prevention program, effectiveness, peer based drug prevention program, self efficacy, substance abuse.

\section{INTRODUCTION}

During the last forty years a considerable change has been observed in the number and nature of both substancerelated and substance-unrelated addictions, with increasing substance abuse and/or presence of behavioural addictions among juveniles. To counteract this trend, health policy has now been focused more intensively on substance abuse prevention and health promotion [1, 2]. Primary and secondary prevention measures focus specially on young persons, since puberty is a phase of life when life crises and new behavioural habits tend to play an essential role, including the testing and possibly 'solidification' of harmful forms of behaviour $[3,4]$.

The danger of juvenile addiction is mostly assessed by means of prevalence and incidence rates. While the data

*Address correspondence to this author at the 1080 Wien, Lerchenfelderstraße 144-146/3, Vienna, Austria; Tel: 0043/676/9240462;

E-mail: dorothea.stella-kaiser@chello.at obtained are not statistically significant, they still suggest a few tendencies:

According to international data it is mostly young people that consume alcohol and tobacco, which is partly due to the social acceptability of these legal substances. Accordingly, these substances exhibit highest prevalence rates [5-8]. As to illegal substances, the use of cannabis is much more frequent than that of other illegal drugs, with amphetamines ranking second [6]. In recent years, however, cannabis use appears to have stagnated in Austria (ÖBIG 2007), while alcohol consumption has doubled. The most rapidly addictive substance is heroin, which is consumed only by a small percentage [6]. Along with statistical data, various studies have investigated addiction risks, all of them showing that massive family problems, lack of social support, life in juvenile shelters, poor education, unemployment and homelessness give rise to problematic consumption behaviour and addiction [9-12]. 
Young people can most easily be approched via school, which acts as a suitable socialisation instrument for both primary and secondary prevention [4, 13]. Rather than merely providing information on addictive substances, new preventive interventions have also sought to convey the message of drug prevention by 'affective programmes' aimed at personality development. In the course of the $1980 \mathrm{~s}$ emerged the life- competence promotion models [1, 14, 15], focusing on human beings rather than substances. Their very content also changed, as the paradigm of pathogenesis was shown to give way to salutogenesis, from drug prevention to more general health promotion $[10,16]$. Educative measures also changed, on the basis of the findings of numerous evaluations, from teacher-centered teaching to an interactive approach [17-21]. As it was observed that addressees' involvement was enhanced by their own activity, multipliers ( multipliers work with students of other grades) were trained to pass on what they had learned about drug prevention. For many years substance use prevention has been based on interactive (long-term) programmes, led either by adults (teachers, experts) or people of the same age group (peers) $[19,22]$.

While experts feel that effective drug prevention is possible [23], results concerning its efficiency are still controversial [24-26]. Many studies suggest the greater effectiveness of peer-based programmes while other evaluations doubt their superiority over adult-led models. Definitive proof is still lacking [23, 28, 31, 32]. In any case, the effectiveness of drug prevention is enhanced by an early start of preventive measures that are broadly conceived rather than one-sided and limited to specific substances, and that address healthy individuals and aim at enhancing life skills [24, 26]. "Today, life-skill approaches are known as the most effective programme types" [26, 27]. The WHO reports that key "life skills approaches" focus on strengthening key life skills like decision making, problem solving, creative thinking, critical thinking, effective communication, interpersonal relationship skills, selfawareness, empathy, coping with emotions, coping with stress [59].

Current literature on drug prevention ranks perceived self-efficacy - though not one of the 'core life skills' - among the chief factors promoting drug prevention [29, 30]; in fact, many authors believe that an increase in self-efficacy as such helps to prevent addiction [29, 30]. Developed in 1977 and subsequently adopted by the social cognitive theory of learning, Bandura's concept defines perceived self-efficacy as the appreciation of one's own capability to tackle the difficulties and barriers encountered in life and the conviction to be able to influence one's life and health by one's own conduct $[33,34,41]$. The significance of perceived self-efficacy for overcoming addiction was examined from different angles: especially in addicts for assessing its role in overcoming their addiction habits [3537], and within the scope of drug abuse prevention to determine its significance for obviating the risks or causation of addiction [13, 38, 39].

Young persons are considered as a particular target group for exploring the significance of perceived self-efficacy and especially the correlation of perceived self-efficacy with general well-being, constitution, school performance and physical activity [40-42]. As regards preventing or delaying drug abuse, special importance attaches to resistance selfefficacy $[30,43,44]$. "Resistance self-efficacy refers to one's perceived ability to resist pressure to drink or use drugs" [58: 292].

\section{MATERIALS AND METHODOLOGY}

The study design did not require the approval of ethics committee, since no drugs or pharmaceuticals were administered, nor were the study participants the clients of a hospital. Informed consent was obtained from the parents of the students.

Two drug prevention programmes - a peer-based and an adult-led programme - were conducted at two secondary schools over a period of 42 months. In the peer-based intervention students discussed drug-related subjects with their peers (classmates or others), either directly or indirectly (by informal communication). The approach generally considered most effective in the long term is the grass-roots or diffusion approach [45]. Peer educators were presented the subject in an interactive and playful way comprising both substance-specific and non-specific issues [2]. Special attention was paid to ensuring that peer educators were wellversed in the subject and capable enough to argue their case before their classmates [23]. Their training, which focused on participants' own experience and practical issues, was in the form of one weekend seminar per year as well as weekend seminars three-to-four-hour training units at sixweek intervals.

In the case of the adult-led intervention, all matters of addiction prevention were directly presented by prevention experts, who worked with their audience interactively on all practical matters concerning their personal experience. The experts were academically trained psychologists and psychotherapists having experience in primary, secondary and tertiary drug abuse prevention. The subject matter discussed in the course of drug prevention classes in the individual grades was similar to the one conveyed to students in the course of the peer project

Both of the intervention programmes focused on the enhancement of "life skills" and "self-efficacy"; in the peerled program the peer leaders were instructed in workshops about those issues, while in the adult-led program experts directly trained the students.

Similarly to the Peer Group Education of 'euro net' [23], the project involved some 20 students of grades 5 and 6 of a secondary school to achieve the project objectives for the targeted groups; they acted both as 'peer educators' ('peer educators' work directly with students of their own school grades) and as multipliers (multipliers work with students of other grades). Before the start of the project, a seminar was conducted by the experts for the selection of peer educators and mulltipliers on the basis of such criteria as their social competence, self-image, emotional stability, ability to deal with conflicts and criticism, and their capacity to form and handle groups.

The study was focused on investigating the general effects of drug prevention projects on self-efficacy and substance use, on differences in the effectiveness of peerbased and adult-led drug prevention schemes, and on effects 
encountered within the scope of the peer-based model. Data were statistically confirmed by the odds ratio, the independent sample t-test, the Friedman test and correlation and variance analytical methods. The programme known as Statistical Package for the Social Sciences (SPSS) Version 13.0 was used for data analysis.

\section{Evaluation}

The population investigated - some 400 individuals comprised students of grades 3 to 6 in two Viennese secondary schools. Participants were queried at intervals over a period of four years. On account of the study design these consisted of student cohorts that were under investigation for a maximum of four school grades (see Fig. 1). Accordingly, the sample sizes differed at the various assessment points on account of drop-outs, students that had to repeat the year and newcomers on the one hand and the number of students in the respective school grades on the other. In fact, at assessment point 5, the sample was left with only three senior grades.

Concomitantly with the two drug prevention projects a four-year longitudinal study was carried out in the form of a multi-group plan with repeated measurements. After a baseline survey all students of school grades 3 to 6 underwent a pre-test during the first semester (assessment point 1). During the intervention phase - i.e. the activity of peers and experts - a first intermediate measurement was taken at the end of the first school year (assessment point 2), and a year later the measurement was repeated (assessment point 3), followed in the course of the subsequent year by a post-test measurement (assessment point 4). After a year without intervention, the results were then followed up at assessment point 5 to test the stability of the effect of the interventions

In the interest of compliance with validity criteria, steps were taken to ensure comparability between the schools and to keep assessment methods and instruments constant; a standardised method was introduced for which interviewers were specifically trained $[46,47]$. The questionnaire remained the same throughout the period under investigation and the time allotted for filling in the questionnaire was the duration of one lesson (50 minutes). The requirements of anonymity of respondents, objective evaluation and constant conditions under which they were queried were painstakingly complied with. Questionnaire items were formulated unequivocally and allowed graduated answers in order to avoid acquiescence [46].

A questionnaire comprising 101 questions developed on the basis of a standardised procedure was used at five different points in time to assess the effectiveness of the two drug prevention programmes. The questions in the general part were about sociodemographic and health data, while the five more specific parts dealt with self-efficacy, consumption behaviour, coping strategies and emotional states, the role of school and other aspects of the subject's life, and his/her wellbeing. The most significant parts of the questionnaire were:

General part: Data concerning age, gender, school grade, peer activity and sociostatistical data have been focussed in general part. Items were formulated along the lines of customary questionnaires relating to the social situation of juveniles, such as 'Health Behaviour in Schoolaged Children (HBSC) "or ESPAD 2003 [48, 49].

Self-efficacy: In the field of self-efficacy one of the core issues the questionnaire dealt with was whether a distinction can be made between general perceived self-efficacy and resistance self-efficacy. The questionnaire was to assess selfefficacy on the basis of the general perceived self-efficacy scale of Jerusalem/Schwarzer 1999, the psychometric parameters of which are rated as good, with an internal consistency of Cronbachs alpha between 0.78 und 0.79 . Correlation findings establish its criteria-related validity [50].

Perceived resistance self-efficacy was measured by the 'perceived self-efficacy in handling drugs' scale by Bäßler/Mittag (1999). The three items related to the rejection of alcohol, cigarettes and drugs gave respondents a choice
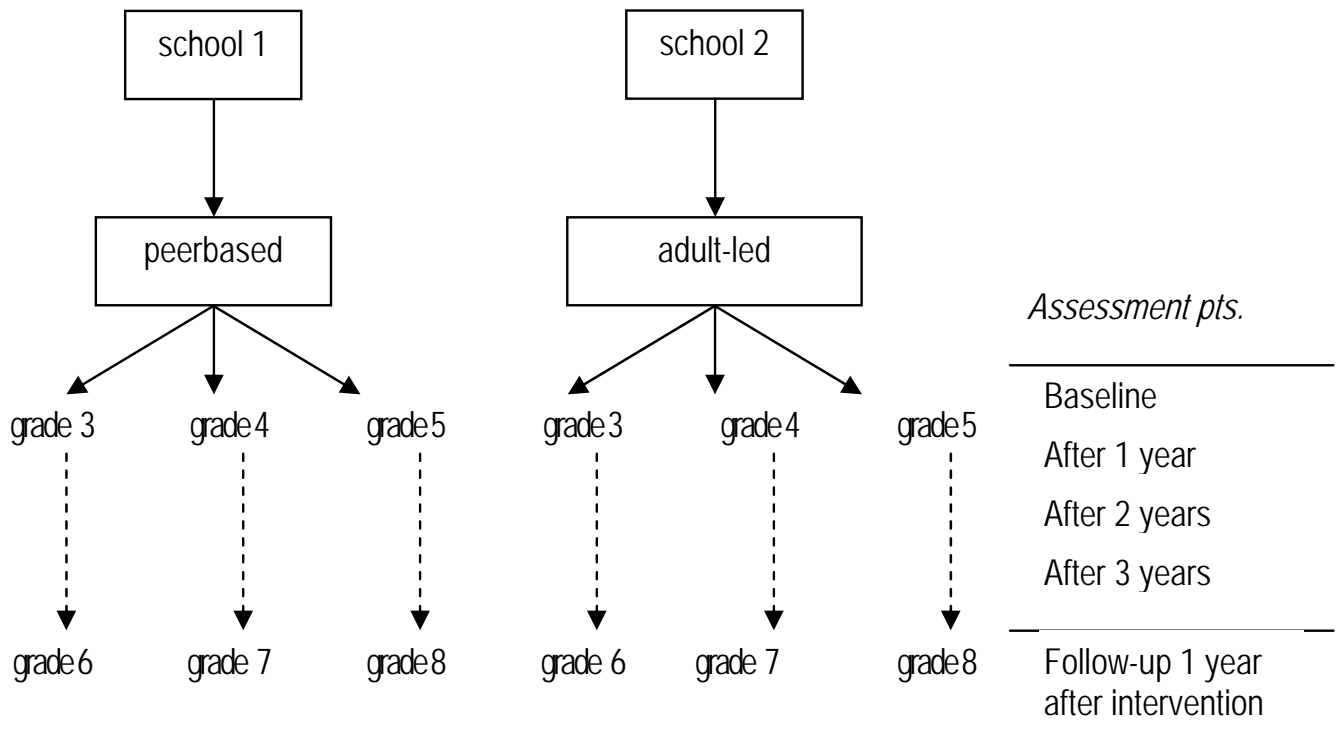

Fig. (1). Study design. 
between four answers ranging from four answers from 'does not apply' to 'applies fully'. The scale's factor validity is generally accepted [50].

Consumption behaviour: This part dealt with substance use by the juveniles, particularly the first and current use of tobacco, alcohol and illegal drugs. Along the lines of ESPAD Austria 2003 [49] the questions concerned first use of nicotine, age at first use, current use of nicotine and extent of use, alcohol consumption, frequency and kinds of alcohol consumed. As to illegal substances, a detailed list of drugs was presented and subjects were asked whether they had used any of them at least once, several times or frequently over the last twelve months.

\section{RESULTS}

\section{Demographic Particulars}

In all, 398 students participated in the study. After exclusion of cases that could not be evaluated, the sample was left with $376(94.5 \%)$ students, 60.6\% (228) from the secondary school with peer education (G 1) and 39.4\% (148) from the school with an adult-led intervention $(G 2)$. The discrepancy between sample sizes in the two schools is explained by the study design, which for pragmatic reasons had to include all students of the respective grades in the absence of exclusion criteria other than inappropriate responses. In the course of the plausibility test and data reassessment a number of questionnaires and their authors had to be eliminated from the sample since it became clear upon data imput that the questionnaires had not been correctly answered.

Gender distribution was similar in the two schools, with roughly 45\% (167) boys and 56\% (208) girls. Average age was 15 years, ranging from 12 to 19 years. Average age at the first assessment point (prior to onset of the intervention) was approx. 13.7 years, at assessment point 5 (follow-up) approx. 16.7 years.

All peer educators were students of G1. All in all, 37 $(16.3 \%)$ students worked as peer educators and (nine of them throughout the period under investigation), i.e. $4 \%$ of the total sample from G1 and slightly less than a quarter $(24.3 \%)$ of the peer population. Of the 37 peers, 11 were male $(29.7 \%)$ and $26(70.3 \%)$ female. These percentages suggest that girls felt more deeply committed to their peer activity than boys.

\section{Consumption Behaviour}

Alcohol: Over the entire period of investigation, 94.1\% of students in the two groups stated that they had tried alcohol at least once. $71.6 \%$ (222 students) had drunk alcohol at least once prior to the intervention, and $65.6 \%$ of the peer educators and $76.2 \%$ of non-peers from G1 $(n=196)$ had also done so. No statistically significant differences were found between the two schools, nor were there any genderspecific distinctions. It is worth noting that as many as $37.3 \%$ of 12 -year-olds and more than two thirds $(69.3 \%)$ of 13 -year-olds admitted they had already drunk alcohol at least once, indicating that experimenting with alcohol started at an early age.

Prior to the intervention $43.2 \%$ of the total sample stated that they never drank alcohol, while $15.5 \%$ were found to drink alcohol regularly - i.e. daily or weekly - and another $41.3 \%$ occasionally (once a month or less), preferably lemonades with alcohol $(34.4 \%)$ or other alcoholic beverages such as long drinks or cocktails $(36.6 \%)$. At onset, both occasional and current alcohol consumption did not differ in terms of gender or peer educator activity.

One fifth (18.6\%) of the 12-year-olds and more than half the 13-year-olds (54.5\%) were currently drinking alcohol. From age 14 onwards six out of ten and from age 15 even eight out of ten students were found to be users of alcohol. On closer analysis no significant difference was observed between the two intervention models as regards the risk of alcohol consumption. One year after onset of the intervention the risk of alcohol consumption was reduced by a factor of 0.9 in school G1 as compared with G2, indicating that students benefited from the peer-based intervention, but this benefit was merely descriptive and not statistically relevant (OR: 0.9; CI 95\% = 0.596-1.586). All other assessment points, however exhibited no benefits neither descriptively nor at the level of inferential statistics. Accordingly, students in the peer-led group did not show any significantly lower risk of alcohol consumption.

Some interesting effects were revealed in an in-depth analysis of those students who consumed alcohol regularly: In both schools roughly $15 \%$ of students were drinking alcohol regularly prior to the intervention; at assessment point 2 this percentage dropped, if only slightly, to $13.7 \%$ in G1 while it increased to $19.8 \%$ in the other school. By the end of the intervention, the share of regularly drinking students at school G2 (adult-led intervention) was significantly higher, at $48.3 \%$, than that of students at the school using the peer-based model (33.3\%): At school G1 the risk of regular alcohol consumption was clearly reduced by a factor of 0.5 (OR: 0.5 ; CI $95 \%=0.310-0.923$ ) by the end of the intervention. At follow-up, the risk of regular alcohol consumption was, in purely descriptive terms, reduced by a factor of 0.8 in school G1 (44.4\%) as compared with G2 $(50 \%)$, but the better long-term effect of the peer-led intervention did not prove to be statistically significant (OR: 0.8; CI 95\%=0.445-1.439) (see Fig. 2).

Among the peer educators, the risk of post-intervention alcohol consumption was found to be 1.5 times higher than that of their fellow students, but this effect is not statistically significant: working as a peer educator did not result in any change in alcohol consumption.

Tobacco: Over the entire period of investigation a total of $73.1 \%(n=275)$ of the students were found to have smoked a cigarette, cigar or pipe at least once. Before the intervention $41.4 \%(n=128)$ had smoked at least once while more than half $(58.6 \%)$ of the total student population $(n=309)$ had never done so. In the case of tobacco consumption, peer educators hardly differed from their non-peer colleagues. First-time tobacco consumption was found to be the same, at roughly $41 \%$, for both schools and in both genders. As expected, age made a difference, as it did with alcohol consumption (eta $=0.419 ; \mathrm{p}=0.000): 17.2 \%$ of the 12 -yearolds stated that they had already smoked at least once, and amongst those aged 16 only $12.5 \%$ reported that they had never smoked. Slightly more than a quarter $(27.3 \%)$ of $13-$ year-olds and almost two thirds $(62.3 \%)$ of those aged 15 had consumed nicotine at least once. 


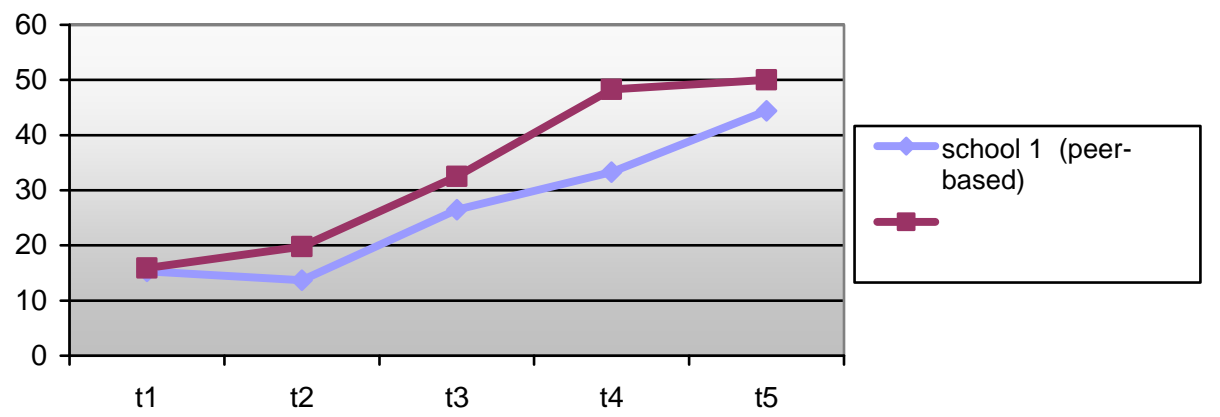

Fig. (2). Percentage of students consuming alcohol regularly as a function of the intervention model over time.

As regards their current use of tobacco, $15.3 \%(n=47)$ of the total number of 308 were reported to be smokers at assessment point 1 . Of these, $42.6 \%$ were daily and $29.8 \%$ weekly smokers. $27.7 \%$ stated that they rarely smoked. At assessment point 1 more girls $(18.2 \%)$ than boys $(11 \%)$ reported to be smokers, but the difference between the sexes was just not statistically significant $\left(\chi^{2}=2.999, \mathrm{p}=0.083\right)$. Prior to the intervention no statistically significant difference was noted between the two schools as far as the proportion of smokers was concerned the proportion of smokers (CI $95 \%=0.661-2.488)$, even though the smoking risk was 1.3 times as high in the peer-intervention school (G1) as compared with G2 (13.3\%). One year after the start of the intervention, however, the ratio was reversed, with the smoking risk slightly reduced among the peer-led group $(\mathrm{OR}=0.9)$ : While the proportion of smokers remained constant in school G1 (16.9\%) it increased to $18.2 \%$ in school G2. This trend actually continued and intensified up to the time of follow-up; immediately after the end of the intervention (assessment point 5) the risk of smoking was clearly higher, but not significantly so, among the students of school $2(37.1 \%)$, as compared with those of G1 (26.6\%) $(\mathrm{OR}==.6)$.

The share of smoking peer educators was 2.2 times higher, at $28.1 \%$ (CI $95 \%=0.895-5.299$ ) than that of nonpeers $(15.2 \%)$, a difference that remained constant over the entire run of the project. One year after the intervention, however, the proportion of smokers among the non-peer participants was higher, at $28.8 \%$, than that of peer educators $(23.5 \%)$, a difference that was, however, not statistically significant $(\mathrm{OR}=0.763$; CI 95\% $=0.225-2.585)$.

While the influence of the peer-led drug prevention programme on nicotine consumption may be described as positive, its superiority was not found to be statistically significant at any assessment point.

Illegal Substances: Over the entire period of investigation as many as 159 students $(42.3 \%)$ had some experience with illegal drugs at least once. Prior to the intervention 241 out of 307 students $(78.5 \%)$ had no contact or experience with illegal substances, while $66(21.5 \%)$ were found to have already consumed illegal substances once or several times. The use of Cannabis products was most frequently mentioned (by 17.6\%), followed by the use of inhalants (glue, solvents) at $4.9 \%$. All other illegal substances ranked at $3 \%$ or less. Although no gender specific differences were found, marked increase in 'one-off' experience was, as expected, observed with increasing age from $3.4 \%$ of 12 year-olds to $50 \%$ of those aged $16(\eta=0.395)$. While $15.2 \%$ of participants in the adult-led intervention admitted that they had at least once consumed illegal substances, the corresponding proportion for the peer-led group (G1) was reported to be one quarter $(25.1 \%) \quad(\mathrm{OR}=1.876$; CI $95 \%=1.020-3.449)$. It should be noted that the higher risk of drug experience among peer educators $(38.7 \%)$, though not statistically significant, was 2.2 times as high as that of nonpeers $(22.6 \%)$ (OR: 2.2 , CI 95\%=0.964-4.874) (see Fig. 3).

When queried about their drug consumption within the last 12 months, $18.2 \%$ of the students stated prior to the intervention that they had consumed illegal substances. $14.5 \%$ cited cannabis products (joints, grass, marihuana or hashish), while $4.2 \%$ were found to rely on inhalants such as glue or solvents. While more girls $(20.1 \%)$ consumed drugs than boys $(15.5 \%)$, the gender difference was not statistically significant $\left(\chi^{2}=1.070, \mathrm{p}=0.301\right)$.

Prevalence rates for the consumption of illegal substances fluctuated only slightly during the last 12 months of the project: The proportion of users amounted to $18.2 \%$ before the intervention dropped to $17.7 \%$ at assessment point 2 and rose from assessment point 3 to reach approx. $24 \%$ at point 5. At assessment point 1 the risk of drug consumption was significantly higher (by a factor of 2.2) in school G1 as compared to the one in school G2 (OR: 2.2; CI 95\%=1.1144.251), and remained higher at all the other assessment points, even though the ratio was statistically insignificant. The Cochran Q-Test showed statistically significant changes in consumption behaviour at both schools. The peer-led model proved to be more effective in controlling drug use as it resulted in only a slight increase of $3.9 \%$ over the period under investigation, as compared with a $10.2 \%$ increase in the adult-led intervention. This appears to confirm that a peer-led intervention in may reduce or delay the increase in substance use somewhat more effectively than the other form of intervention.

A comparison between current drug use by peer educators and school-mates in school G1 showed that the peer educators had, prior to the intervention, significantly more experience with illegal substances $(37.5 \%)$ than their fellow students of the same age $(20.5 \%)(\mathrm{OR}=2,323$; CI $95 \%=1,026-5,260)$. This significant difference persisted throughout the project. A reversal of the trend was indeed observed one year after the end of the intervention, when $23.5 \%$ of the peer educators and $26.5 \%$ of their fellow students of the same age reported drug use during the past 12 months, but this difference was not significant $(\mathrm{OR}=0.853$; CI $95 \%=0.251-2.896)$. Still, drug experience remained 


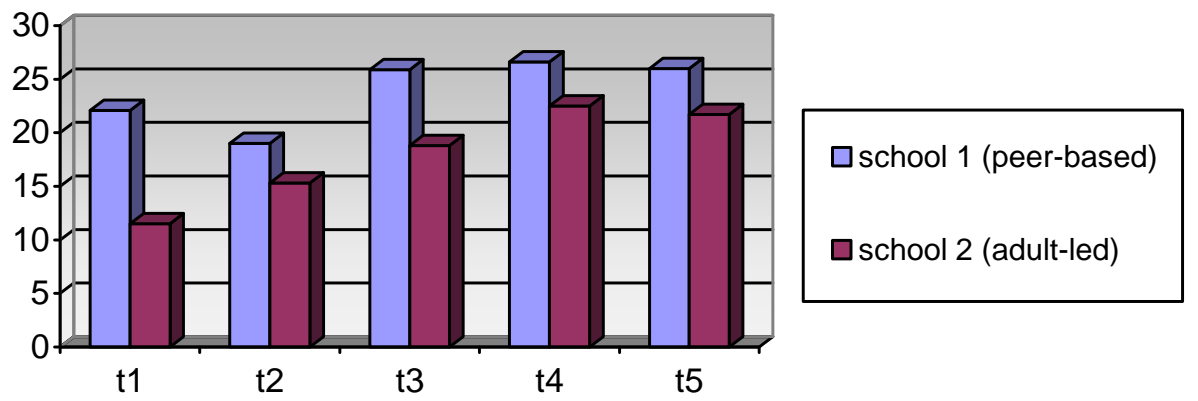

Fig. (3). Consumption of drugs in percent as a function of intervention model over time.

clearly higher in the case of peer educators than with their fellow students.

The greater drug experience of the peer educators could perhaps be one of the reasons behind their active participation on the project; on the follow up however their drug use behaviour showed a consolidation, resulting in lower drug consumption compared to their schoolmates. The reason for this phenomenon is still unclear and needs further examinations.

The school which ran the peer-led project showed a higher initial rate of illegal substance use, which remained, however, fairly constant over the course of the project, while a sharper increase in drug use was noted in the adult-led intervention.

In summary, it can be stated that, as far as drug use was concerned, no significant difference was found empirically between the adult-led and the peer-based drug prevention programmes. It was only noticed in the case of habitual alcohol consumption that the peer-led model proved more effective than the adult-led one, in that the risk of regular alcohol consumption exhibited a definite decline immediately after the end of the intervention.

Positive effects of the peer-based approach may be evident by the fact that it resulted in a slower rate of increase in the use of illegal substances throughout the period of intervention than was the case with the adult-led model.

\section{Perceived Self Efficacy}

Even before the onset of the intervention, perceived general self-efficacy of the students was fairly high (averaging 3.054 points; $\mathrm{SD}=0.3818$ ). A high rating - from 3.0 points upwards - was found in $62.9 \%$ of the students in question, while slightly more than one third showed a low degree of perceived self-efficacy. There were no differences in terms of gender and age.

A longitudinal study based on the Friedman Test revealed a significant increase in perceived general selfefficacy to an average of 3.190 points on follow-up $\left(\chi^{2}=33.312, p=0.000\right)$. Likewise, the percentage of students with a high perceived self-efficacy (3.0 and up) rose from $62.9 \%$ to $78.6 \%$ one year after the intervention. Thus, selfefficacy is shown to have increased over the period of investigation (see Fig. 4).

While school G2 initially showed a significantly higher general self-efficacy rating (3.128 points; $\mathrm{t}=2.533, \mathrm{p}=0.012$ ) than school G1, a difference that remained significant at all times despite an increase in self efficacy, follow-up (at assessment point 5) showed a reduction of the inter-school difference $(t=1.937, p=0.054)$. This would suggest that both intervention models are capable of enhancing self-efficacy.

Examining the connection between perceived selfefficacy and substance use, we observe an increase in alcohol consumption during the investigation period, as expected, but a causal relationship with perceived general self-efficacy could only be established to a limited extent: only at assessment point 2 were individuals with a low degree of perceived self-efficacy found to drink significantly more than those with a high degree of perceived self-efficacy $(\mathrm{OR}=2.061$; CI $95 \%=1.191-3.567)$. One year after the intervention, alcohol consumption by high-self-efficacy students remarkably was remarkably higher than it was than the one in the cohort showing a low degree of self-efficacy $(\mathrm{OR}=0.187$; CI $95 \%=0.063-0.555)$. No gender-specific effects were noted, nor did a comparison between students with a high degree of self-efficacy in either intervention model reveal any statistically significant difference; participants in the peer-led programme with a lower degree

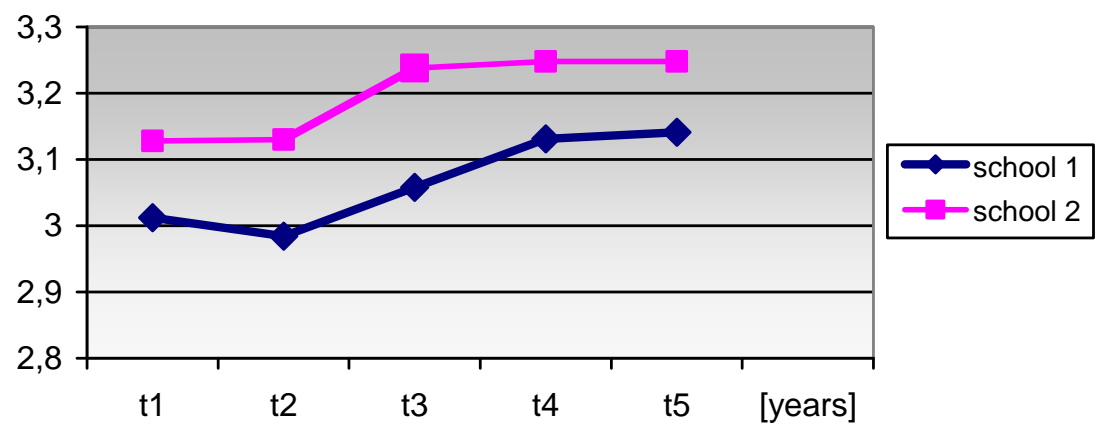

Fig. (4). Average perceived general efficacy by school. 

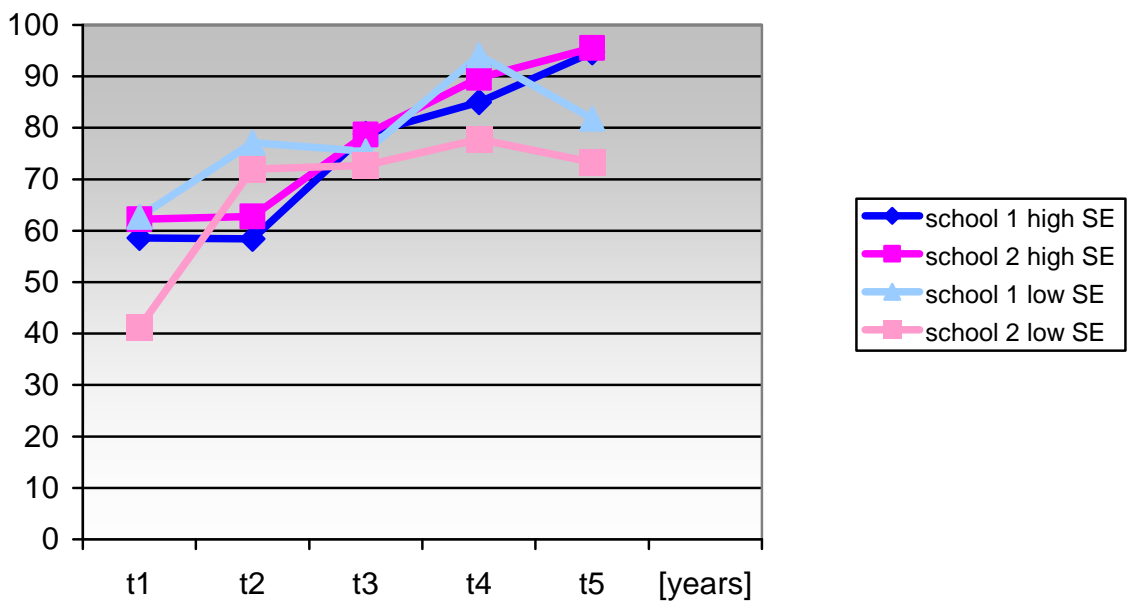

Fig. (5). Alcohol consumption as a function of perceived general self-efficacy and intervention model.

of self-efficacy drank more alcohol at all assessment points, though the difference was statistically significant only before the intervention $(\mathrm{OR}=2.398$; CI $95 \%=1.048-5.488)$. On follow-up students with high self-efficacy from both schools stated that they were clearly drinking more alcohol than their counterparts in the low-self-efficacy group. This means that a high degree of confidence in one's self-efficacy does not result in lower alcohol consumption. Apparently, a high degree of confidence may result in the conviction that alcohol consumption is well under control, so that the individuals concerned tend to drink more heavily (see Fig. 5).

As regards nicotine consumption, perceived general selfefficacy was not found to affect the students' smoking behaviour. No gender-specific differences or differences in respect of the level of self-efficacy were found. An agespecific effect determined by means of variance analysis (GLM) was proved to be statistically significant only in the case of smoking $(\mathrm{F}=7.998, \mathrm{p}=0.000)$, but, as in the case of alcohol consumption, it proved impossible to establish any connection with self-efficacy $(\mathrm{F}=0.316, \mathrm{p}=0.867)$.

Only immediately after the end of the active intervention did students in the peer-led group (G1) with a high degree of perceived self-efficacy smoke significantly less than their counterparts in the adult-led group (G2) ( $\mathrm{OR}=0.483$; CI $95 \%=0.246-0.948)$; an year after the intervention the difference was no longer significant $(\mathrm{OR}=0.758$; CI $95 \%=0.371-1.548)$. Students with little perceived self-

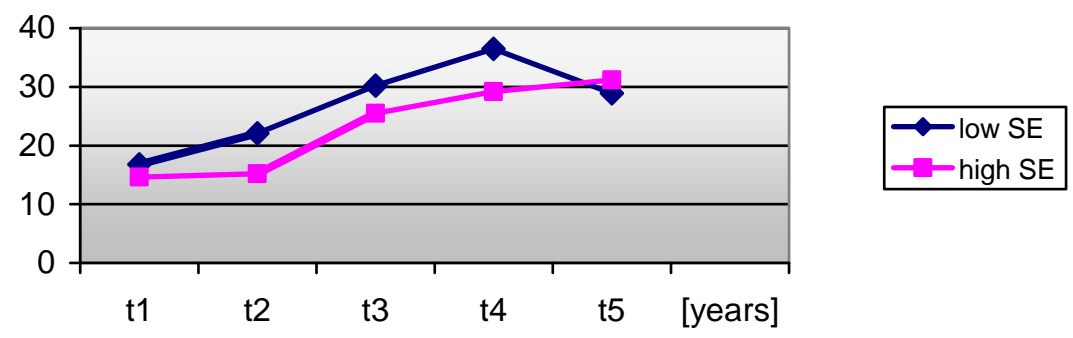

Fig. (6). Smoking behaviour as a function of perceived general self-efficacy over assessment points.
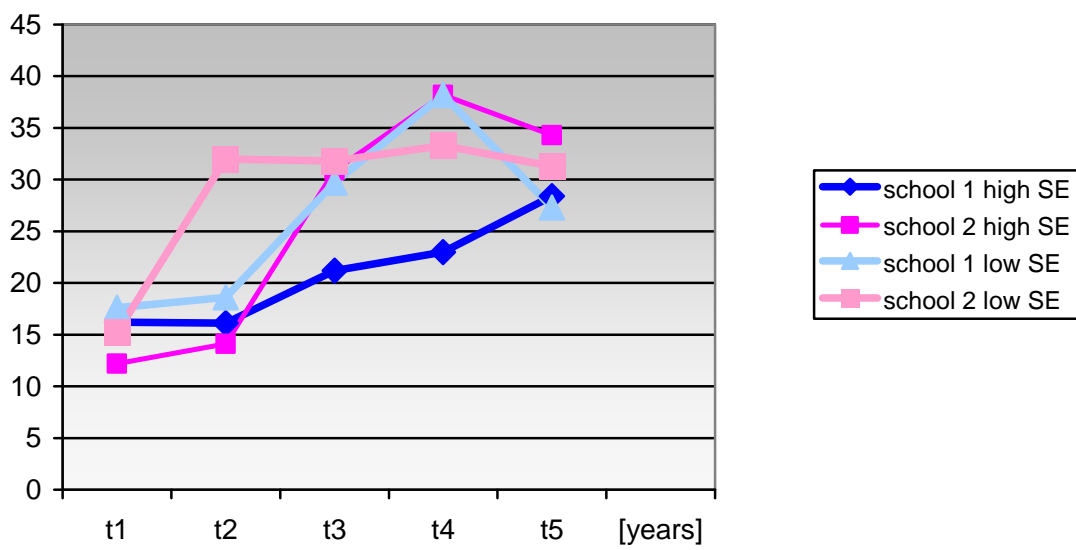

Fig. (7). Percentage of smokers in the two schools as a function of perceived self-efficacy. 


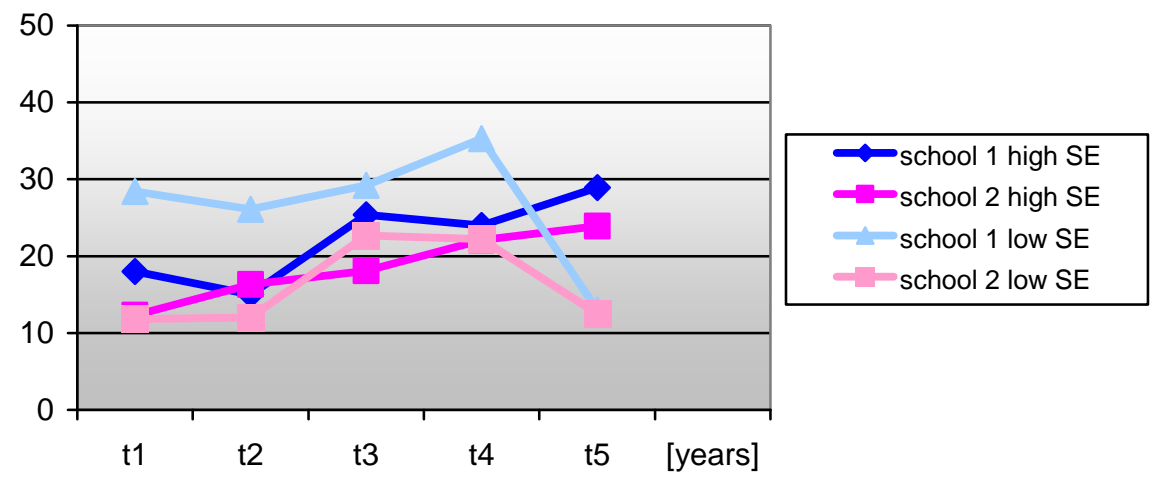

Fig. (8). Consumption of illegal substances as a function of perceived self-efficacy and intervention model.

efficacy did not reveal any significant difference at any point in time (see Figs. 6, 7).

Regarding the effect of perceived self-efficacy on substance use it should be noted that in comparison with alcohol consumption and smoking a rather low proportion of some $20 \%$ of students stated that they used illegal substances. As anticipated the proportion of cannabis users was found to be the largest. The present study did not establish any statistically significant connection between perceived self-efficacy and substance use, nor were there any statistically significant gender-specific differences attributable to self-efficacy, while the age effect was significant, as expected $(\mathrm{F}=14.359, \mathrm{p}=0.000)$.

Comparison between the two schools shows that illegal substance use was higher in school G1 (peer-led intervention), particularly in those students with a low level of self-efficacy. The large proportion of illegal substance users with a low level of self-efficacy in the peer-based model extended from assessment point 1 to assessment point 4 but dropped dramatically one year after the intervention. Again, statistically significant effects were not found at any assessment point (Fig. 8).

At assessment point 2, peer educators with a high level of perceived self-efficacy exhibited a 3.5 times higher risk of drug use $(\mathrm{OR}=3.583$, CI $95 \%=1.046-12.281)$, and at assessment point 4 an even 8 times higher risk than their counterparts $(\mathrm{OR}=8.214$, CI $95 \%=2.565-26.303)$. Among peer-educators with a low level of perceived self-efficacy, a similar effect was observed at assessment point 3 $(\mathrm{OR}=3.455$, CI $95 \%=1.053-11.330)$.

\section{Resistance Self-Efficacy}

Prior to the intervention, the students' perceived resistance self-efficacy ratings averaged 3.706 points $(\mathrm{SD}=0.511) .94 .2 \%$ exhibited a high level (3.0 and above) of self-efficacy in coping with drugs; girls, with an average of 3.781 points, were better than boys (average 3.602) $(\mathrm{t}=3.077$, $\mathrm{p}=0.02)$; no age-specific differences were found $(\mathrm{F}=1.722$, $\mathrm{p}=0.145)$.

A longitudinal analysis did not reveal any change in selfefficacy ratings $\left(\chi^{2}=7.075, \mathrm{p}=0.132\right)$. The proportion of students with a high level of self-efficacy against drugs remained high, ranging from $94 \%$ to $98 \%$.

The inter-school comparison showed that it was only during and immediately after the onset of the intervention that self-efficacy changed in favour of students in the peerled group: While the level of self-efficacy was high in both schools, students under the peer-led regime showed a significantly higher drug resistance self-efficacy than their adult-led counterparts both at assessment point $3(\mathrm{t}=1.992$, $\mathrm{p}=0.047)$ and point $4(\mathrm{t}=2.005, \mathrm{p}=0.046)$. By follow-up, the two schools' ratings had consolidated at the same high level $(t=1.143, p=0.254)$. This means that in the course of the intervention the peer-led model produced a more marked increase in perceived resistance self-efficacy than did the adult-led programme.

An analysis of the development of perceived resistance self-efficacy as a function of peer education in the school running the peer model revealed no difference between peer educators and non-peers.

\section{DISCUSSION}

The object of the present four-year study was a comparison of an adult-led and a peer-based drug prevention project regarding their influence on the development of selfefficacy and the substance-use behavior of secondary-school students.

Discussion of the results concerning consumption patterns To summarise briefly the findings about students' consumption behaviour, it may be said that while the higher effectiveness of the peer-led model as compared with the adult-based one was not statistically significant regarding alcohol, nicotine and drug use, the peer-led approach at least exhibited a somewhat more positive effect on consumption behavior in that immediately after the intervention the risk of regular alcohol consumption was clearly reduced and that, over the period of the intervention, illegal substance use increased less strongly among students in the peer-led group than it did in the adult-based model. These findings are in agreement with various authors $[15,17]$ who also considered peer education model to be the more effective approach to addiction prevention.

It may be concluded from the data regarding alcohol that the peer-led scheme has a more positive effect on drinking behavior than the adult-based programmes, since the risk of regular alcohol consumption immediately after the end of the intervention remarkably reduced amongst the students in the peer-led group.

A comparison of alcohol consumption among peer educators and their classmates showed that after the 
intervention the risk of drinking alcohol was 1.5 times higher among the peer educators than the one among their classmates; this difference was, however, not statistically significant. It may thus be assumed that acting as peers neither promoted nor reduced alcohol consumption. Similarly, in the case of tobacco consumption, no significant differences were found between the peer educators and their classmates. By contrast, peer educators showed consistently greater experience with illegal substances (which may to some extent explain their interest in participating in the peer project), though by the time of follow-up their behavior had consolidated at a lower level of drug use.

To sum up, we conclude that as far as the consumption patterns are concerned, a significant difference between the substance use by students in the peer-based and the adult-led prevention programmes cannot empirically be established, except for alcohol consumption at the assessment time point immediately after the end of the active intervention and the fact that the consumption of illegal substances increased less quickly; at the same time the smoking risk was also lower. Neither effect was, however, confirmed statistically.

\section{Discussion of the Results Concerning Self-Efficacy}

The results of analyses of self-efficacy show that, while, general perceived self-efficacy did increase in either case over the period under review, the study failed to confirm a clear superiority of the peer-based model over the adult-led one. Still, both forms of intervention appear to have resulted in an increase in general self-efficacy, showing significant improvements in either case. This may suggest that peer-led prevention programmes should be run continuously within the context of the regular curriculum, which might be instrumental in reducing or at least delaying the risk of habitual alcohol consumption on the part of students. In agreement with numerous authors [18, 19, 26, 39, 52], our results appear to support the assumption that drug-prevention measures at school make sense, particularly when they aim to promote self-efficacy.

On the other hand, general perceived self-efficacy is a variable that may be affected by various factors (cf. [33, 54]). According to Goren/Wright [18] effectiveness studies often encounter many different problems caused by "disturbing variables", i.e. possibly uncontrollable (external) influences that may affect the programmes. However the authors of the present study endeavored to bring such interferences under control, their influence on the outcome cannot be fully ignored.

From a longitudinal perspective, our results failed to give evidence of any change in resistance self-efficacy. This is all the more surprising as resistance self-efficacy is generally regarded to have a particular protective effect on substance use and health-related behavior [55-57]. One possible explanation of this finding may be that the students included in the present study had right from the beginning a high degree of resistance self-efficacy, so that their share remained high throughout the study period, with only slight variations within the range of $94 \%$ und $98 \%$. At the same time it should be noted that participants in the peer-based project showed a significantly higher level of self-efficacy regarding drug use, both in the course of the study and immediately thereafter, than did the students participating in the adult-led programmes. This may well mean that the peerled model in keeping students' confidence in their own capability to handle drugs at a high level than the adult-based model.

\section{Discussion of the Results Concerning the Connection Between Self-Efficacy and Substance Use}

While an increase was noted in general self-efficacy, this increase exerted only a marginal influence on substance use, and that only in respect of smoking. More specifically, it was observed that immediately after the intervention students in the peer-led group with a high level of perceived selfefficacy smoked significantly less than students in the adultbased project; this difference was, however, no longer significant on follow-up. It should be noted that while students in either project that showed a high perceived selfefficacy tended to smoke less (by 2 to $7 \%$ ) in purely descriptive terms, their smoking risk did not show any decline at any assessment point. This results contradicts, at least partly, the findings reported by some authors, such as Kähnert [30] and Woodruff et al. [39].

Before and during the intervention the percentage of students showing a low level of perceived self-efficacy who admitted using illegal substances was consistently higher than the percentage of high-self-efficacy students, but the differences were not significant, neither generally nor as a function of the intervention.

Discordances were, however, noted in the case of alcohol consumption: While students with a low perceived selfefficacy were found to have drunk more alcohol than their high-level counterparts only at one assessment point during the course of the intervention, this effect was found to have been reversed on follow-up. In accordance with the investigations of McKay et al. (2005) as well as Warren et al. (2007), this could mean that a high level of general perceived self-efficacy might indeed go hand in hand with less alcohol consumption, but only for the duration of the prevention interventions. Still, the present findings at least suggest that a high level of perceived self-efficacy does not necessarily lead to a lower alcohol intake. In fact, a high level of self-confidence might result in an individual's drinking more because $\mathrm{s} / \mathrm{he}$ is convinced to have his/her alcohol consumption under control.

Investigating the effect of resistance self-efficacy on substance use was found to be unnecessary since the majority of students evinced a high degree of self-efficacy with respect to drugs, rendering a statistical analysis of the nexus pointless. A small group of students who showed a low level of perceived resistance self-efficacy throughout the period under investigation did, however, show a marked tendency to consume substances - i.e. tobacco, alcohol and drugs much more frequently than their counterparts with a high perceived resistance self-efficacy. This finding is in agreement with those of other authors discussing the influence of resistance self-efficacy on consumption behavior (cf. [29, 30, 53]. While not statistically significant, this result also suggests that a low level of perceived resistance self-efficacy might give rise to higher substance consumption, an assumption that would require further detailed investigations into this particular factor. In this connection it might also be useful to see whether perceived 
resistance self-efficacy constitutes the only decisive factor or if there are still other intrapersonal factors that might stimulate consumption.

In her study, Kähnert [30] stressed that addiction prevention programmes should be focused on the influence of peers and on promoting resistance training to resist social pressure. In this context the author attributes less importance to a cognitive approach to the subject than to repetitive training focusing on concrete behavior patterns such as turning down drug offers.

On account of the finding of that at least immediately after the end of the three-year project, self-efficacy had some relevant impact on consumption (in this case, smoking) behavior - students in the peer-led group with a high level of perceived self-efficacy were smoking significantly less at that point in time - addiction prevention programmes might, as a first step, benefit from the strategic use of methods designed to enhance self-efficacy as part of health promotion and addiction prevention programmes. The social climate, and indirectly also teaching, would profit from strategies designed to develop social competences and to promote cooperative efforts in the interest of a favourable social climate and the resulting experience of social recognition, encouragement of initiative and team spirit (collective coping) (cf. Jerusalem 2007).

Various authors (cf. $[18,58]$ ) surmise that the peer educators themselves benefit more from addiction prevention programmes than do their classmates. However, in our study, an analysis of the development of perceived general selfefficacy and resistance self-efficacy as a function of peereducator activity failed to evidence any difference between peer-educators and their classmates, which may suggest that peer-based prevention programmes may be beneficial for all students, not only the - relatively small - group of peer educators.

Still, it must be pointed out that in our study the peer educators had at least as much (if not more) experience with substance use as their classmates, and that this experience inspired them to take an active part in the project. One open question is whether this greater experience causes them to call their own consumption patterns into question, as is suggested by Benschop et al. (2002), Franzkowiak/ Schlömer (2003) or Kempen (2007), or whether they serve as a negative example, as is assumed by Goren/Wright (2006).

Moreover, the leveling of differences observed on follow-up - particularly in the case of alcohol consumption might suggest that addiction prevention programmes in schools should be run continuously over an extended period. One might, with all due caution, conclude from the present findings that it would be beneficial for schools - the only institutions where all juveniles aged 10 to 15 years can easily be approached - to operate continuous addiction prevention and health promotion programmes, preferably based on peer educators, possibly even as a regular part of the everyday syllabus.

From an academic point of view it would be important to monitor and evaluate long-term prevention programmes in schools, and to integrate both process and result evaluation a regular part of school health promotion projects. In concrete terms, it would be helpful to see what variables other than self-efficacy should be given special attention, and in what way their investigation could be promoted.

\section{LIMITATIONS}

Methodologically, our approach could conceivably be criticized in so far as the use of a questionnaire might, in spite of numerous plausibility tests, result in overestimated or underestimated prevalence rates, an aspect also emphasized by Strizek et al. (2008) [8]. Even though the authors of the present study used standardized and timetested instruments, they feel compelled to raise the fundamental question of whether the effects of addiction prevention programmes can actually be properly evaluated. Some references in the literature actually discuss the issue of whether the general effects of prevention programmes can at all be operationalised and measured [51].

Another point of possible criticism could be the discrepancy between sample sizes in the two schools: But as stated above - this can be explained by the study design, which for pragmatic reasons had to include all students of the respective grades in the absence of exclusion criteria other than inappropriate answers.

A further point of criticism is that the present study fails to unequivocally prove the effectiveness of addiction prevention programmes at school level in influencing substance use by juveniles. Even though the peer-led project was seen, in purely descriptive terms, to have a positive effect it failed to prove its superiority over the adult-based project and did not exhibit any long term effect. One possible flaw in the present study might be the absence of a control group of persons not involved in any addiction prevention scheme.

This criticism may be countered by pointing out that the basic assumption from which the authors started was that addiction prevention held promise in each and every case so that the focus of the investigation was on different methods of addiction prevention and their respective effectiveness, which was to be investigated by means of a pragmatic comparison between the peer-led and adult-based models. This appeared all the more urgent as relevant statements in the literature on the effectiveness of peer education programmes still lack sufficient statistical confirmation. It is true that the present study has only provided marginal evidence in favour of the peer-led model. The one finding on which most authors investigating peer education agree is that young person's prefer to be informed about health promotion by their peers. With only few exceptions, most references conclude that participants in peer education programmes declare themselves highly satisfied. Generally, interactive methods are preferred to didactic ones such as lectures or teacher-centred teaching.

In the interest of health promotion research, it would be advisable to continue in-depth investigations into what other risk and protection factors may influence consumption behavior, addiction risk and the genesis of addiction. What else can be done to bring a decline in substance use or delay its onset? What other factors ought to be taken into consideration when designing programmes? Kähnert (2003) emphasized in this context that addiction prevention programmes should "not only aim at changing individual 
attitudes and forms of behavior ("Verhaltensprävention") but should also be accompanied by a change in overall healthrelated conditions ("Verhältnisprävention")". While this claim appears to be justified, the question arises (a) whether the former can have a lasting effect for all unless it is backed up by the latter, and (b) to what extent peer education programmes are not in themselves interventions that aim at changing overall conditions (i.e. forms of "Verhältnisprävention"). Starting from the premise that the introduction of a peer programme in a school will of its own accord bring about a change in the system "school", it would be worthwhile to investigate whether the school as a social subsystem might not become an "addiction-preventive system" or, to put it differently, a health-promoting school. Not unlikely, the environment in which both the protagonists (peer educators) and the recipients (target group, classmates) live and act is changed by the very implementation of such a programme, in that, for one thing, the attention of all those concerned is focused on the subject of health promotion and addiction prevention and, for another, all persons involved in the school and in school activities need to be reconsidered. In the process, inveterate - rational and irrational, social and emotional - patterns are abandoned in favor of a healthpromoting approach.

\section{CONCLUSIONS}

Meaningful and effective addiction prevention schemes should thus necessarily focus on promoting and strengthening self-efficacy. As regards perceived selfefficacy, the peer-led model appears to have a slightly greater impact on the development of perceived self-efficacy than the adult-based approach.

On the basis of the findings of the present study it can be recommended that addiction prevention projects should preferably take the form of peer-led schemes; they should be implemented in the form of permanent continuous features of the syllabus, since the effects of addiction prevention efforts normally appear immediately after the intervention and tend to decline in the course of time.

In accordance with Kähnert (2003) we would also suggest that prevention programmes should preferably be started before health-damaging forms of behavior appear. "One-off "events (such as project days) tend to be ineffectual and require long-term, continuous efforts. The long-term effect of projects can only be ensured by continuity, whereas projects limited in time produce only minor long-term effects. The present study shows that changes tended to be strongest at the end of the intervention period and had already declined by the time of follow-up, suggesting that health-promoting measures should be permanent in nature.

\section{CONFLICT OF INTEREST}

The authors confirm that this article content has no conflict of interest.

\section{ACKNOWLEDGEMENTS}

Declared none.

\section{REFERENCES}

[1] Franzkowiak P, Schlömer H. Entwicklung der Suchtprävention in Deutschland: Konzepte und Praxis. Suchttherapie 2003; 4: 175-82.
[2] Uhl A, Springer A. Professionelle Suchtprävention in Österreich: Leitbildentwicklung der Österreichischen Fachstellen für Suchtprävention. Wien: Bundesministerium für soziale Sicherheit und Generationen 2002.

[3] Uhl A, Gruber C. Suchtprävention. In: Brosch, R./Mader, R. (Hrsg.): Sucht und Suchtbehandlung. Problematik und Therapie in Österreich S, Ed. Wien: LexisNexis 2004; pp. 393-419.

[4] Bäuerle D, Israel G, Rasel D. Suchtvorbeugung in den Schulen der Sekundarstufen I und II. Band I: Konzeption, Fachliche Grundlagen, Rechtsaspekte. Soest: Landesinstitut für Schule und Weiterbildung 2001.

[5] Hibell B, Andersson B, Bjarnasson T, et al. The ESPAD report 2003. Alcohol and other drug use among students in 35 European countries. Stockholm: The Swedish Council for Information on Alcohol and Other Drugs (CAN), Council of Europe, Co-operation Group to Combat Drug Abuse and Illicit Trafficking in Drugs (Pompidou Group) 2004

[6] Österreichisches Bundesinstitut für Gesundheit (ÖBIG). Bericht zur Drogensituation. Wien: ÖBIG 2007.

[7] Österreichisches Bundesinstitut für Gesundheit (ÖBIG). Bericht zur Drogensituation. Wien: ÖBIG 2008

[8] Strizek J, Uhl A, Schmutterer I, et al. ESPAD Austria 2007: Europäische SchülerInnenstudie zu Alkohol und anderen Drogen. Band 1: Forschungsbericht. Wien: Bundesministerium für Gesundheit 2008.

[9] Klein M. Kinder und Suchtgefahren. Risiken, Prävention, Hilfe. Stuttgart: Schattauer Verlag 2008.

[10] Giacomuzzi S. A Contribution to the understanding of the addiction phenomenon. Innsbruck: University Press 2008.

[11] Petraitis J, Flay BR, Miller TQ, Torpy E, Greiner B. Illicit substance use among adolescents: A matrix of prospective predictors. Subst Use Misuse 1998; 33: 2651-4.

[12] Raithel J. Risikoverhaltensweisen Jugendlicher. Ein Lehrbuch. Wiesbaden: VS Verlag für Sozialwissenschaften 2004.

[13] Rühling E, Stich M, Hartwig C. Frühinterventionen bei Suchtgefährdung. Ein Überblick. Suchttherapie 2004; 5: 60-9.

[14] Botvin GJ. Preventing drug abuse through the schools: Intervention programs that work. In: National Institute on Drug Abuse (Ed.): NIDA - National Conference on Drug Abuse Prevention Research 1996. Plenary Session 3. Available from: [http://archives.druga buse.gov/meetings/CODA/Schools.html; 27.09.2011].

[15] Cuijpers P. Peer-led and adult-led school drug prevention: a metaanalytic comparison. J Drug Educ 2002; 32(2): 107-19.

[16] Locher B. Notwendigkeit und Möglichkeit suchtpräventiver Maßnahmen im Interventionsfeld des jugendlichen Vereinssports. Dissertation. Heidelberg: Ruprecht-Karls-Universität 2001

[17] Cuijpers P. Effective ingredients of school-based drug prevention programs. A systematic review. Addict Behav 2001; 27(6): 100923.

[18] Goren N, Wright K. Peer education as a drug prevention strategy. Prevent Res Q 2006; 17: 3-20.

[19] Gottfredson DC, Wilson DB. Characteristics of effective schoolbased substance abuse prevention. Prevent Sci 2003; 4(1): 27-38.

[20] Bundesministerium für Wirtschaft, Familie und Jugend (BMWFJ) (Hrsg.) 4. Bericht zur Lage der Jugend in Österreich. Teil B: Prävention in der außerschulischen Jugendarbeit. Wien: BMWFJ 2011.

[21] Tobler NS, Roona MR, Ochshorn P, Marshall DG, Streke AV, Stackpole KM. School-based adolescent drug prevention programs: 1998 Meta-Analysis. J Primary Prevention 2000; 20(4): 275-336.

[22] Hanewinkel R, Wiborg G. Effektivität verhaltenspräventiver Interventionen zur Suchtvorbeugung. Suchttherapie 2003; 4: 18391.

[23] Kern-Scheffeldt W. Peer-Education und Suchtprävention: Such Magazin 2005; 5(05): 3-10.

[24] Heppekausen K. Intrapersonales Risiko für Substanzmissbrauch und differentielle Wirksamkeit eines suchtpräventiven Lebenskompetenzprogramms. Dissertation, Münster: Wilhelms-Universität 2005.

[25] Lohaus A, Domsch H. Psychologische Förder- und Interventionsprogramme für das Kindes- und Jugendalter. Heidelberg: Springer 2008.

[26] Maiwald E, Bühler A. Effektivität suchtpräventiver Lebenskompetenzprogramme. Ergebnisse deutscher Evaluationsstudien. In Landesinstitut für Erziehung und Unterricht Stuttgart (Hrsg.): Suchtvorbeugung, Gesundheitsförderung, Lebenskompetenz. Eine 
Handreichung für die Lehrerinnen und Lehrer für Information zur Suchtprävention in Baden-Württemberg. Sonderausgabe 15: LifeSkills-Modelle. Stuttgart: Landesinstitut für Erziehung und Unterricht Stuttgart 2004.

[27] Weichold K. Prevention against substance misuse: life skills and positive youth development. In: Silbereisen KR, Lerner RM, Eds. Approaches to Positive Youth Development. London: Sage Publications 2005; pp. 293-310.

[28] de Vries H, Mudde A, Leijs I, et al. The European smoking prevention Framework Approach (EFSA): an example of integral prevention. Health Educ Res 2003; 18(5): 611-26.

[29] Barkin SL, Smith KS, Du Rant RH. Social skills and attitudes associated with substance use behaviors among young adolescents. J Adolesc Health 2003; 30(6): 448-54.

[30] Kähnert H. Evaluation des schulischen Lebenskompetenzförderprogramms „Erwachsen werden“. Dissertation. Bielefeld: Universität Bielefeld 2003.

[31] Foxcroft DR, Ireland D, Lowe G, Breen R. Primary prevention for alcohol misuse in young people. Review. Cochrane Database Syst Rev 2002; 3: CD003024.

[32] Bals Th, Hanses A, Melzer W. (Hrsg.) Gesundheitsförderung in pädagogischen Settings: Ein Überblick über Präventionsansätze in zielgruppenorientierten Lebenswelten. Weinheim: Juventa 2008.

[33] Bandura A. Self-efficacy. Towards a unifying theory of behavior change. Psychol Rev 1977; 84: 194-215.

[34] Bandura A. Self-efficacy. In: Ramachaudran, VS. (Ed.): Encyclopedia Hum Behav 1994; 4: 71-81. New York: Academic Press [Reprinted in Friedman, H. (Ed.): Encyclopedia of mental health. San Diego: Academic Press 1998]

[35] Martin RA, Rohsenow DJ, MacKinnon SV, Abrams DB, Monti PM. Correlates of motivation to quit smoking among alcohol dependent patients in residential treatment. Drug Alcohol Depend 2005; 83(1): 73-8.

[36] McKellar J, Ilgen M, Moos BS, Moos R. Predictors of changes in alcohol-related self-efficacy over 16 years. J Subst Abuse Treat 2008; 35(2): 148-55

[37] Schell TL, Orlando M, Morral AR. Dynamic effects among patients' treatment needs, beliefs, and utilization: a prospective study of adolescents. Drug Treat Health Serv Res 2005; 40(4): 1128-47.

[38] Schuck AM, Widom CS. Childhood victimization and alcohol symptoms in women: an examination of protective factors. J Stud Alcohol Drugs 2003; 64: 247-56.

[39] Woodruff SI, Conway TL, Edwards CC. Sociodemographic and smoking-related psychosocial predictors of smoking behavior change among high school smokers. Addict Behav 2008; 33(2): 354-8.

[40] Kral K. Gesundheitsbezogene Wirkungen von asiatischen Kampfkünsten am Beispiel der Sportart Karate in Österreich. Das fernöstliche Bewegungskonzept als multiples Instrument zur Förderung der Gesundheit. Dissertation. Wien: Universität Wien 2009.

[41] Schwarzer R. Psychologie des Gesundheitsverhaltens. 2. überarbeitete und erweiterte Auflage. Göttingen: Hogrefe 1996.

[42] Robbins SB, Lauver K, Le H, Davis D, Langley R, Carlstrom A. Do psychosocial and study skill factors predict college outcomes? A meta-analysis. Psychol Bull 2004; 130(2): 261-88.
[43] Bandura A. Social foundations of thought and action. New Jersey: Prentice Hall 1986.

[44] Reinisch A. Tabakentwöhnung für Jugendliche: empirische Befunde und Grundzüge eines verhaltensorientierten Interventionskonzeptes. Weinheim: Juventa 2007.

[45] Svenson GR. European guidelines for youth AIDS peer education. Brüssel: European Commission 1998.

[46] Bortz J, Döring N. Forschungsmethoden und Evaluation. Für Human- und Sozialwissenschaftler. 4. Auflage. Berlin: Springer 2006.

[47] Schnell R, Hill P, Esser E. Methoden der empirischen Sozialforschung. 8. Auflage. Oldenbourg: Wissenschaftsverlag 2008.

[48] Ludwig Boltzmann-Institut für Medizin- und Gesundheitssoziologie HBSC/17. Gesundheit und Gesundheitsverhalten bei Kindern und Jugendlichen. Ergebnisse des 6. WHO-HBSC-Surveys im Schuljahr 2001/02 und Trends von 1990 bis 2001. Wien: Bundesministerium für Soziale Sicherheit und Generationen 2002.

[49] Uhl A, Bohrn K, Fenk R, et al. ESPAD Austria 2003: Europäische Schüler- und Schülerinnenstudie zu Alkohol und anderen Drogen, Band 4: Fragebogen. Wien: Bundesministerium für Gesundheit und Frauen 2005b.

[50] Schwarzer R, Jerusalem M. (Hrsg.) Skalen zur Erfassung von Lehrer- und Schülermerkmalen. Dokumentation der psychometrischen Verfahren im Rahmen der Wissenschaftlichen Begleitung des Versuchs Selbstwirksame Schule. Korrigierte Web Version. Berlin: Freie Universität 2001.

[51] Uchtenhagen A, Wicki W. Evaluation im Bereich der Primärprävention. In: Uchtenhagen, A. Zieglgänsberger, W. (Hrsg.): Suchtmedizin. Konzepte, Strategien und therapeutisches Management, S. 254-258. München: Urban \& Fischer 2000.

[52] Orlando M, Ellickson PL, McCaffrey DF, Longshore DL. Mediation analysis of a school-based drug prevention program: effects of Project ALERT. Prevent Sci 2005; 6(1): 35-46

[53] Hurrelmann K. Lebensphase Jugend. Eine Einführung in die sozialwissenschaftliche Jugendforschung. Weinheim: Juventa 1999.

[54] Finke L, Williams J, Ritter M, et al. Survival against drugs: education for school-age children. J Child Adolesc Psychiatr Nurs 2002; 15(4): 163-9.

[55] McKay JR, Foltz C, Stephens RC, Leahy PJ, Crowley EM, Kissin W. Predictors of alcohol and crack cocaine use outcomes over a 3 year follow-up in treatment seekers. J Drug Abuse Treat 2005; 1: S73-82.

[56] Warren JI, Stein JA, Grella CE. Role of social support and selfefficacy in treatment outcomes among clients with co-occurring disorders. Drug Alcohol Depend 2007; 89(2/3): 267-74.

[57] Jerusalem M. Entwicklungs- und Gesundheitsförderung durch Stärkung von Kompetenzen. Vortrag beim 5. Augsburger Nachsorgesymposium am 29./30. Juni 2007.

[58] Marlatt GA, Baer JS, Quigley LA. Self-efficacy and addictive behavior. In: Bandura, A. (Ed.): Self-efficacy in changing societies. New York: Cambridge University Press 1995; pp. 289-315.

[59] World Health Organization (WHO). Life skills education for children and adolescents in schools. Introduction and Guidelines to Facilitate the Development and Implementation of Life Skills Programmes. Geneva: World Health Organization 1997. 